\title{
Audiences Meanings on Figure Disabilities in Korean Drama Scarlet Heart
}

\author{
Ahmad Khairul Nuzuli \\ Master of Communication Studies, Faculty of Social \\ Diponegoro University \\ Semarang, Indonesia \\ ahmad.nuzuli@gmail.com
}

\begin{abstract}
This study aims to find out how the representation of disabled characters in Scarlet Heart and how audiences interpret the character discrimination with disabilities in Scarlet Heart. Scarlet Heart Korean Drama 2016 has become the first Korean drama who obtain 11.3 rating. Representations store physical disabilities in Scarlet Heart using the system code and the language of film. This drama emphasizes physical differences figure prince Wang Soo (Lee Joon Gi), a prince who has a disability due to a scar on the face, and he is depicted wearing a mask to cover the wound. The paradigm of this research is critical paradigm that assumes there is always an unfair structure, the media is considered to be a tool that is used by certain people in power to marginalize the other. Other meanings beyond the meaning that has been determined precisely marginalized. By using the analysis of the work of Stuart Hall reception, this study involved five informants from a series of indepth interviews. Results showed that $80 \%$ of informants in a dominant position hegemonic and $20 \%$ remaining in the position negotiated. Meanings informant influenced previously owned personal knowledge was then supported by the dominant ideology discriminative meaning against disabled people are represented through the film.
\end{abstract}

Keywords—reception analysis; disability; film

\section{INTRODUCTION}

Television is one of the most popular mass media in Indonesia. According to research results Nielsen Television is still the main medium consumed by Indonesian people (95\%), then Internet (33\%), Radio (20\%), Newspapers (12\%), Tabloid $(6 \%)$, and Magazine (5\%) [1]. And one of the content that is often consumed through television is Film.

Sobur said that the film is able to form and bring back reality based on the codes, ideology of the culture [2]. The contents of the film can also be analogous to the current cultural representation. The film can also be one of the media that potentially affect the audience because it has the ability and power to reach many social segments 3 . Seen from a cultural perspective, the mass media (including film) is the main source for presenting a picture of social reality and common identity and presenting a shared cultural environment [3].

The term disability or physical defect itself is also described in the code system and the language of the film. We know the term sinetron for serial films that aired on television.
So, there is a soap opera production of ginseng country, South Korea, which is known as "Korean Drama Series". Representation of the physically disabled person in the Korean drama Scarlet Heart uses the code and movie language system. The highlight is how this drama emphasizes the physical differences of prince Wang Soo (played by Lee Joon Gi), a prince who has a scarred deformity, and is depicted wearing a mask to cover the wound.

The first Korean drama Scarlet Heart was first launched in 2016 has become the first Korean drama to gain an $11.3 \%$ rating in Korea while in Indonesia it has a 9.8\% rating in Indonesia [4]. The Korean drama has also received many awards, one of which is the SBS Drama Awards 2016 where Scarlet Heart earned 7 awards at the same time [5]. In Indonesia, this drama is aired on cable TV One (TV subscription) consisting of 20 episodes aired Monday-Tuesday at 22:00 pm from 29 August to 1 November 2016.

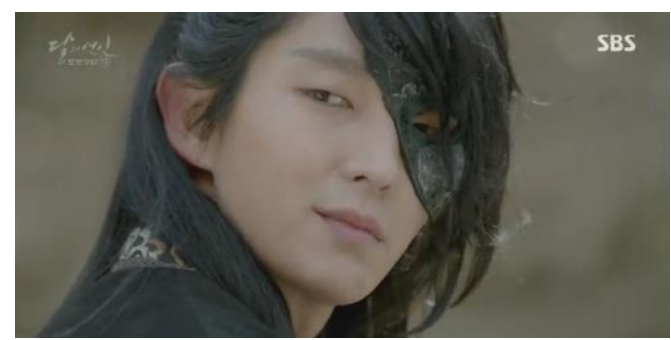

Fig. 1. Prince Wang Soo

In the narrative, prince Wang Soo as a physically handicapped. Prince Wang Soo's life along with other figures who have normal body and face emphasize the importance of observations related to the symbol system of the behavior of its characters. Therefore, the symbolic behavior that emerges is one of the important things in this representational system. In this case, the movie scene display helps to affirm a certain meaning in the reality and social construction of Prince Wang soo's life. Social construction according to Dominick in the film also includes choreographers created by the film's creators who helped shape the image of Prince Wang Soo [6].

In addition to the story about the physical disability, the background of Prince Wang Soo's life details in the show. Among the causes of defects in the face, life lived, behavior, relationships with family and the environment that has a normal face / body. In this case the creator tries to invite the 
audience to share the emotional experience of Prince Wang Soo and the audience feels empathetic with him. How his physical disability becomes a supporting factor and obstacle for him. Because as marginal and minority, disabled people with physical disabilities are often categorized as "abnormal" and always violate the rules of other figures [7]. The efforts of representation of the disabled to be a major influence in this study. Because the pronunciation process of Prince Wang Soo's character answers the ignorance of the general public about the issue of disability in which the physical differences in a person are used as guidelines for obtaining different behaviors. The implications affect the way audiences perceive characters. Because audiences are invited to enter the side of film ideology in the form of representation that is represented [8].

To be able to enjoy a movie audience does not require literacy, but the audience is required to have media literacy capabilities. Ensuring watching is not just an activity of consumption but also the production of meaning. The audience is required to be an active audience, which views the audience as an active producer of meaning. The audience as an active audience must also act as a producer of meaning. Korean drama is a crucial issue because it presents a diffable character. Because if viewed from the rating, this film has a relatively large audience. With romantic romance themes and dramas, Korean drama audiences generally range from teens to adults, between the ages of 15 and 25 [9] With many audiences will make a lot of meaning when they receive the text of the film. Whether the audience is dominant in reading, negotiation, or opposition. In this case, the analysis of audience acceptance or reception analysis is used to determine the meaning derived from the audience.

Efforts of marginalization, labeling and discrimination are the basic ideologies used in this study. Because the representation of a character is often an unconscious bias. The audience easily accepts and imitates the values contained in the film. Particularly in interpreting the personality of the disabled and treating the disabled persons with disabilities. Therefore, the interesting author lifted the Meaning of Discrimination of Disabled People in the Korean Drama Scarlet Heart as the title of this research.

Although the regulatory Act (Act) No. 82016 has been asserted with disabilities recognized and have the same rights as other citizens. However, the perception of society is opposite, there are still many perception, marginalization, labeling and public discrimination against PwDs. As the mass media shape the perception of the film also social and cultural, so that what is shown and accepted by the audience and finally recorded into a learning society. Value is in the film as well as an example for audience and into something reasonable.

The meaning of the signs that appear in the whole drama of Korean drama Scarlet Heart is an information. The film has created a labeling that marginalizes people with disabilities, in this case the diffable figure in the film as being considered "weird", gets discrimination from the environment. The text in the film also favors a particular ideology. So that the relation between defective figure which is considered strange and got discrimination become something reasonable by audience as consumer of film.
Audience as the audience are actively engaged in the interpretation of the text. Active audience can only accept the full meaning has its own meaning or even construct meaning out of what is formed by the film. Based on this background, this study tries to answer: How is the representation of disabled characters in Scarlet Heart? How audiences interpret the character discrimination with disabilities in Scarlet Heart?

\section{ReSEARCh Method}

This study uses qualitative descriptive type. The paradigm of this research is critical paradigm that assumes there is always an unfair structure, the media is considered to be a tool that is used by certain people in power to marginalize the other. Other meanings beyond the meaning that has been determined precisely marginalized

There are several steps through which researchers in analyzing the reception. In the reception analysis, researchers should look at how the contextual analysis associated with the mass media discourse and discourse in the mob of characters with disabilities. The explanation can be seen as follows:

- As described in the background, meaning the media against discrimination can be seen by studying the text in the movie. In this study, researchers used a semiotic analysis Fiske with the aim to see the dominant ideology in the movie. Fiske's own semiotic analyze the subtitles into three levels: The first level of reality lies in the written language, such as the transcript of the interview documents and so on. In a television-like behavior, make-up, clothes, speech, movement movements and etc. The second level of representation of the signified technically. In written language just as words, propositions, phrases, images, captions, graphics and so on. In a TV-like camera, music, lighting, and others. Element - the element is transmitted into representational code that includes among others how the objects depicted (characters, narrative, setting, dialogue, and etc.). The third level is organized into coherency element ideology and code - code ideology, such as individualism, socialism, patriarchy, race, class, materialism, and etc. [10].

- The next step is to figure out the meaning of that of the public by conducting ethnographic studies. The first process of ethnographic study is collecting data by conducting interviews. According to Spradley ethnographic study conducted by interviewing ordinary people with specific questions put any topic according to the research theme to build their knowledge and experience description of their general [11]. Data obtained from the informant and then poured into the transcript of the interview. The second step is to analyze the data. From interviews and then analyzed by the researchers to look at the themes of meaning. The next step is to group the meaning of the four informants into three categories of meaning expressed by Stuart Hall, which is the dominant reading, the negotiated reading, and the oppositional reading. To be able to know the meaning informant grouping into categories of meaning, the researchers did a comparison between the 
preferred reading with meaning that is raised by the research informants.

Associated with interviews, teenagers and adults aged 15 to 22 years of age Semarang. Semarang chosen because, according AGBNielsen in 2010 Semarang is a city that has the largest number of television audience in Indonesia. In addition, Semarang also has many migrants, especially overseas students who come from different cultural backgrounds will add to the diversity of meaning as expected. This is in accordance with the opinion of Croteau says that characteristics such as differences in age, race, ethnicity, gender, and economic might need to be considered as a part of social identity diversity and serve as a cultural tool in the study of the meaning of the audience [9] [12]. Included in this study, Researchers determine specific criteria for informants involved in the study. That informant involved ever see Korean dramas Scarlet Heart. Based on these criteria, the researchers then get five informants. researchers find that the five informants are able to do the reading and interpretation of the construction of disabled characters in Korean dramas Scarlet Heart. The following descriptions of the informant:

- Dhea, Age 22 years, a female student majoring in Communication Science Diponegoro University of Semarang.

- Erwin, Age 21, an employee at the Barbershop in Semarang

- Iwan, Age 22 years, an employee of a café in Semarang

- Edo, aged 22 years, a student of mechanical engineering at Diponegoro University in Semarang

- Liza, aged 22 years, a female student majoring in Communication Science Diponegoro University of Semarang.

\section{RESUlT AND DisCUSSION}

A. Representation of People with Disabilities In Scarlet Heart

In this study, researchers divided the object of research into 3 units of analysis using semiotic analysis John Fiske were then discussed by the reality level, the level of representation and ideological level. The unit of analysis were selected based on the focus of the research, which is the meaning of the symbol of discrimination. In distribution, the researchers showed various discrimination signs which will form the meaning of these signs.

First, scene 10 explains flashback of memory wang soo first arrived at Songak. In this scene explain the reasons for the defect Wang Soo's face. In the show with his mother hurt his face Wang so using a knife that causes his face disfigured until now. This is because her mother was fighting with her father, when her father wanted to remarry.

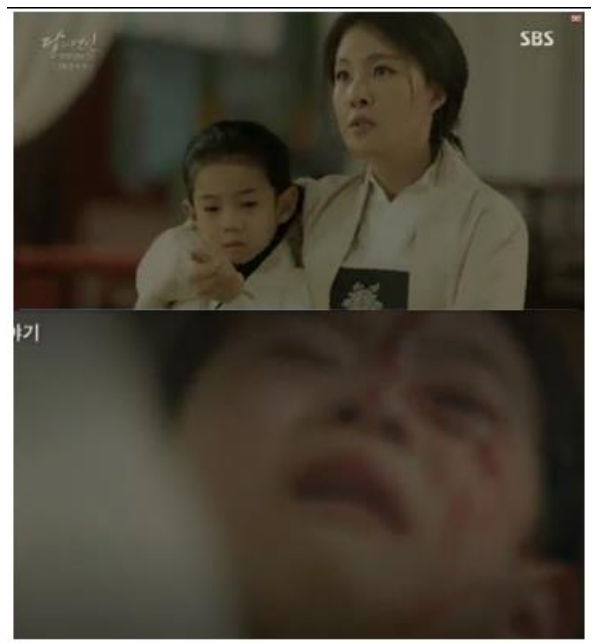

Fig. 2. The face of small Soo Wang injured his mother with a knife

Level reality begins appearance (below) shows the threedimensional makeup depicting gory scars and stories to support future prince kacil Wang Soo to make it look more dramatic and real. Choreography mother embraced and held a knife also explain the cause of the defect in the face of Wang Soo is because his own mother.

At Level Representation beginning of the discussion of camera technique Shotmidle close-up (over) emphasize how his mother was the cause of disability in the face of the prince Wang Soo. Her mother accidentally scraping blade to face because of a fight with Soo Wang's father who wants to get married again. Shot close-up (below) used of stressed conditions due to face Wang Soo knife scratches which eventually leave scars that cause a defect in his face Wang Soo. A case that is expressed in a discriminatory view that disabled people in the media tends to appear as victims of violence. Lighting techniques used by this scene that is using the key light and fill light. As for the music and sound effects are used to use an effect that shows a tension of a scene that lasts. Besides music there is the sound of dialogue shown by the figures and ambient atmospheric scene. This scene is deliberately displayed to notify and play the audience emotions in order to feel the feelings felt by the prince Wang Soo.

The next scene 69 scene arrival of Wang Soo explained to his mother after slaughtering the clergy messengers mother (Queen Yoo) traitors and try to kill Crown Prince Wang Mu. In order for her to be freed of the charges and to cover his tracks. But instead he was rejected by his mother. 


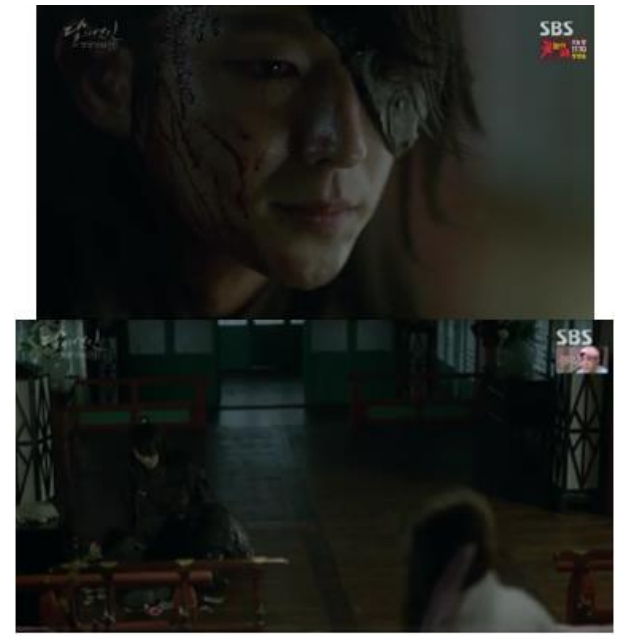

Fig. 3. Prince Wang Soo rejected his mother, Queen Yoo

The level of reality begins in appearance (bottom image) shows a three-dimensional makeup depicting the blood that explains that she just came back from slaughtering the priests. In his dialogue there is an important point from the words of his mother, Queen Yoo "you think I will thank you? Do you want me to ask you are you hurt? You're like an animal. Go away. You smell blood and I can not sleep. Yang explained that her mother would never care even though she had tried to make her mother happy and safe. Also when Prince Wang Soo tells his experience of being dumped at the place of a wolf by the Kang family and trying to make his mother pity him. His mother remained unconcerned and answered why Queen Yoo threw prince Wang Soo to Sinju. The words of the queen yo "A mother confesses only her son that makes her mother glorious. You're a disgrace to me. Dialogue shows that her mother deliberately ostracized her due to her disability making her mother embarrassed. Her mother would feel more comfortable and happy if away from her. In addition to his daily clothing tends to wear black clothes and wear a mask, this represents a mysterious impression on Prince Wang Soo. Wang Soo is repressed shy and hard to socialize with other people.

The level of representation starts from a close-up Shot at the time Wang Soo cries in front of her mother after her mother tells her to accidentally throw it into Sinju because the wound on her face makes it a shame and an unlucky carrier for the mother. Sang Soo's sadness scene will seem more dramatic if taken with a closeup shot. Shooting using angle close ups with downward tracing gives meaning to intimacy and bleakness. Sadness, trauma, and shock attached to the character and nature of Wang Soo are also among the trends of the media that discriminates the disabled, featuring dysfabees who always feel sorry for themselves for being treated differently. While the bottom picture is taken with a long shot technique and the position of Prince Wang Soo is highlighted from the high angle from the view of his mother Queen Yoo above showing selfdestruction when her mother did not want to see it. High angle also implies that Wang Soo's power is more lace than Queen Yoo.

Furthermore, the 370 scene explains how the moment of ritual rain. Wang Soo received orders from the king to succeed the Crown Prince to lead the ritual of asking for rain and marching around the kingdom while praying for rain. Throughout the ritual journey depicted he was thrown land and rock by the community. This is because the public thinks his disfigured face will bring bad luck and make the god will not rain.

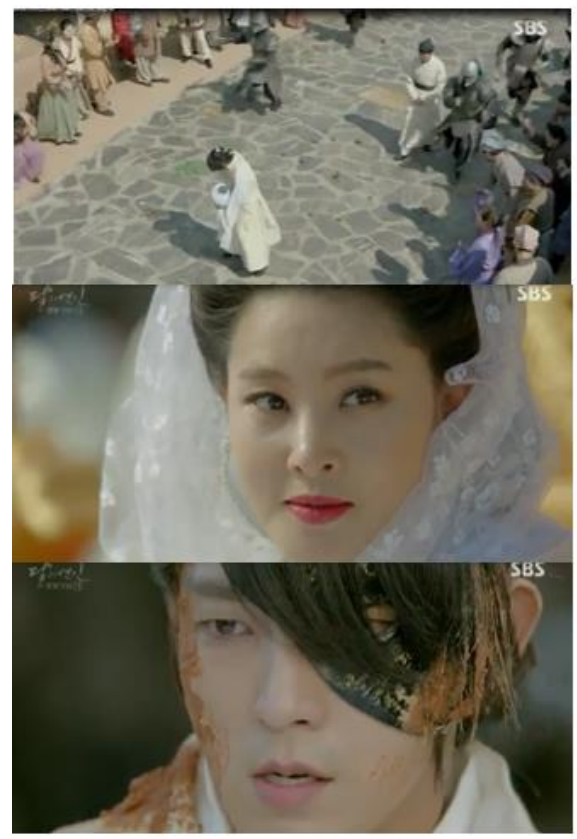

Fig. 4. Wang Soo leads a rain ritual

The level of reality can be seen from the settings that are in the community. From the environmental analysis of society, there is a representational effort in every prince appearing in the midst of society, he is portrayed as feared by everyone. The prince was given the nickname "wolf" because it was considered to be a frightening specter and unlucky bearer in the midst of society. This shows how the representation of the treatment of people with disabilities and non-disabilities. Using three-dimensional make-up, Wang Soo's face was polished with dirt on his face. It aims to attract the audience's emotions to what Wang Soo feels. This indicates the representation of the denial of opportunity and the giving of preference of the work result given to society by the disabled person. There is a difference in the treatment conducted by the public against the personality of the disabled. There is a tendency diffable figures received negative treatment in the form of frightening stereotype, mysterious until ostracized.

Representation can be explained by taking a long shot showing how Wang Soo was thrown and expelled by the community in carrying out the ritual of begging for rain. Through these two shooting techniques it can be seen that the film maker seeks to reveal the context, scope, and distance of the public. This technique is used to show social relationships. With high-angle dominance explicitly portraying Wang Soo's helpless facing scolding and new pitches from the public. This technique also affirms the subject is not capable of anything and can be underestimated. The middle and bottom drawings were taken by using a close-up shot to illustrate how to express his mother's happy expression when Prince Wang Soo was 
thrown using the soil and rocks by the public. While the expression of prince Wang Soo is sad and the pain of being thrown by the community. It represents how suffering and sadness Prince Wang Soo is and how discrimination treats his society and his mother at that time.

Analysis at the ideological level Overall shows the ideology of discrimination against persons with disabilities. This can be seen from the difference in the likes of Wang Soo with other figures. because the physical circumstances make him stereotype a disgrace and bring bad luck from family and society. So, this makes him excommunicated by the community and his family. Accepted forms of treatment are also identical with physical violence, threats, humiliation, exposure, and restraint. In addition, there is another character's attempt not to give opportunity to prince Wang Soo in performing his duties and demonstrating his abilities. Where other figures unilateral determination of each do diffable figures. The existence of physical differences also makes the preference of things done by Wang Soo to contain negative stereotype.

\section{B. Meaning of the audience against discrimination of disabled person in Scarlet Heart.}

Based on the receptionist's analysis of the audience's acceptance of the discriminations of the disabilities in Scarlet Heart, yields two conclusions of acceptance:

1) Opposition Position: Edo, rejecting the form of discrimination against the prestigious male prince Wang Soo. He said that there should be no difference in the treatment of people with disabilities and non-diffable. Discrimination only makes a person suffer. We should provide equal opportunities for disabled and non-disable people. Whether related to work, education and others.

Dhea, rejected the form of discrimination against the disable people of the prince of Wang Soo. He considers the actions of other figures too cruel and make desperate figures despair. He should have been given a chance like any other prince. The role of the family should encourage the disabled diffable to be confident in the activities,

Liza, rejected from society and family against the prince diffable Wang Soo. The provision of dog's stenotype, bad luck and disgrace will only make the disabled person become depressed and suffer. Violence and ostracism against persons with disabilities should not be denied.

Erwin, rejecting discrimination against the disable prince Wang Soo. He argues that discrimination is not something human. Not just for the disabled but also for everyone who is in the minority line.

2) Negotiation position: Iwan, argues that the discrimination against Prince Wang Soo is a natural thing. Wang Soo is one of the figures who are in the minority category, this is what causes him to be discriminated against. But Iwan said that discrimination is not a wise thing in the face of differences. Should all be able to get the same chance between the disabled and the non-disable.

\section{CONCLUSION}

Using Fiske's semiotics analysis at the level of reality, the level of representation, and the level of ideology indicates the ideology of discrimination against the disabled. This is apparent from some scenes that indicate the existence of different attempts to differentiate the character of Wang Soo with other characters. because the physical circumstances make him stereotype a disgrace and bring bad luck from family and society. So, this makes him excommunicated by the community and his family. Accepted forms of treatment are also identical with physical violence, threats, humiliation, humiliation, exposure, and restraint. So that the defect becomes a factor of work can be accepted or not in the community

Using the reception analysis of Stuart Hall shows that $80 \%$ of the audience is in opposition position and $20 \%$ are in the negotiating position. The position of the opposition is influenced by a framework of knowledge previously owned by the informant, about discrimination is something that is not good. This causes unaffected speakers by the dominant ideology in the mass media. While in the opposition position is influenced by the framework of knowledge in the film, but the speakers have their own opinion about the equal rights that must be given to the disable.

\section{REFERENCES}

[1] http://www.romelteamedia.com/2014/08/survei-nielsen-televisi-mediaterpopuler-indonesia.html accessed on 13 November 2017 at $12.20 \mathrm{pm}$

[2] A. Sobur, Semiotics of Communication. Bandung: PT Young Rosdakarya, 2009.

[3] K. Novi, "Consuming Indonesian Gender and Disability In Film," Journal Aspikom vol 3, no. 3, pp. 570-589, June 2017.

[4] http://www.wowkeren.com/berita/tampil/00133126.html accessed on April 2017 at 11:20 pm

[5] http://www.wowkeren.com/berita/tampil/00141864.html accessed on April 20, 2017 at $11.20 \mathrm{pm}$

[6] J.R. Dominick, The Dynamics of Mass Communication. McGrow: Hill Dominick, 1989.

[7] J. Bignell, An Introduction to Television Studies. London : Routledge, 2004

[8] J. Bignell, An Introduction to Television Studies. London : Routledge, 2004 .

[9] H. Martin and S. Steve, Explaining and Understanding International Relations. Oxford: Clarendon Press, 1990.

[10] J. Fiske, Television Culture. London: Routledge, 1987.

[11] J.P. Spradley, Metode Etnografi. Terjemahan oleh Misbah Yulfa. Elisabeth.Yogyakarta : PT Tiara Wacana Yogya, 1997.

[12] D. Croteau, Media / Society: Industries, Images, and Audiences 4th editio. London: London SAGE Publications Ltd., 2013. 